\title{
Analysis of KatG Ser315Thr Mutation in Multidrug Resistant Mycobacterium tuberculosis and SLC11A1 Polymorphism in Multidrug Resistance Tuberculosis in Central Development Region of Nepal Using PCR-RFLP Technique: A Pilot Study
}

\author{
Raunak Shrestha ${ }^{1}$, Rubin Narayan Joshi ${ }^{1}$, Kriti Joshi ${ }^{1}$, Bal Hari Poudel ${ }^{2}$ and Bhupal Govinda \\ Shrestha ${ }^{1}$ \\ ${ }^{1}$ Department of Biotechnology, Kathmandu University, Dhulikhel, Nepal. \\ ${ }^{2}$ Genetics Nepal Pvt. Ltd., Lalitpur, Nepal.
}

\begin{abstract}
Ser315Thr mutations in genes encoding the mycobacteria catalase-peroxidase (KatG) has been associated with the major resistance to isoniazid (INH) in Mycobacterium tuberculosis (MTB). Also G/C polymorphisms in INT4 region of the solute carrier family 11 member 1 gene (SLC11A1) and susceptibility towards tuberculosis (TB) has been demonstrated worldwide. 24 drug resistant MTB culture positive samples and 24 whole-blood samples were collected from different TB patients of Central Development Region of Nepal in 2009. A Polymerase Chain Reaction (PCR) - Restriction Fragment Length Polymorphism (RFLP) assay was carried out in order to investigate Ser315Thr KatG mutation and G/C polymorphism in INT4 region. $4(16.67 \%)$ samples out of 24 MTB culture samples demonstrated the Ser315Thr KatG mutation whereas none of the 24 whole blood samples were found to contain G/C polymorphism in INT4. Though no significant correlation could be found between INT4 polymorphism and TB susceptibility, overall scenario of Nepal cannot be drawn from this data. Molecular diagnostic technique such as PCR-RFLP can be used in a robust scale to carry out base line studies in the TB population of Nepal.
\end{abstract}

Key words: Multi-drug resistance, Tuberculosis, PCR, RFLP

Correspondence Author:

E-mail: sraunak@gmail.com

\section{Introduction}

During the last decades, incidence of tuberculosis (TB) has increased in many countries and more people have the disease now than at any other time in history. It is estimated that TB still kills more people globally than any other infection (WHO, 2009). The situation has worsened by the emergence of antibiotic-resistant strains of Mycobacterium tuberculosis (MTB) (Musser, 1995). The strains resistant to the two most important anti-TB drugs, rifampin (RIF) and isoniazid (INH) are commonly defined as multidrug resistant (MDR). Drug resistance in $M$. tuberculosis is attributed primarily to the accumulation of mutations in the drug target genes; these mutations either leading to an altered target or to an alternation in effective titration of the drug (Rattan et al., 1998).

In 2008, there were an estimated 8.9-9.9 million incident cases of TB, 9.6-13.3 million prevalent cases of TB (WHO, 2009) and 390,000-510,000 cases of MDRTB (WHO, 2010). Among the incident TB cases globally, 3.6\% (95\% confidence interval (Cl): 3.0-4.4) are estimated to have MDR-TB. Almost $50 \%$ of MDR-TB cases worldwide are estimated to occur in China and India. In 2008, MDR-TB caused an estimated death of 150,000 people across the globe (WHO, 2010).

WHO estimated the prevalence of all types of tuberculosis cases for Nepal to be 67,546 
$(240 / 100,000)$. The proportion of MDR-TB in Nepal was $2.9 \%(95 \% \mathrm{Cl}: 1.8-4.3)$ among new cases and $11.7 \%$ (95\% Cl: 7.2-17.7) among retreatment cases (NTC, 2009).

In 2009, with the assistance of WHO, National TB Center in collaboration with National Anti-Tuberculosis Association (NATA) and German Nepal Tuberculosis Project (GENTUP) had conducted a surveillance of extremely drug-resistant tuberculosis (XDR-TB) among the registered MDR TB patients. The study showed a prevalence of $5 \%$ of XDR-TB cases among MDR TB cases registered (NTC, 2009).

Isoniazid (INH) is one of the important first-line tuberculosis drugs. MTB is highly susceptible to INH, with a Minimum Inhibitory Concentration (MIC) of 0.03 $-0.06 \mathrm{mg} \mathrm{ml}^{-1}$. INH inhibits the biosynthesis of cell wall mycolic acids (long chain $\alpha$-branched ß-hydroxylated fatty acids), thereby making the mycobacteria susceptible to reactive oxygen radicals and other environmental factors (Rattan et al., 1998). It is a prodrug that requires activation by the MTB catalaseperoxidase enzyme (KatG) to its active form. Mutation of the KatG gene, which leads to loss of or reduced catalase-peroxidase activity, is a major mechanism of INH resistance in MTB (Musser, 1995). Although various mutations in the KatG gene have been reported in $\mathrm{INH}$-resistant isolates, the most common mutation is the Ser315Thr mutation, which is present in approximately $50-90 \%$ of all INH-resistant isolates, is associated with relatively high-level resistance to INH (Mokrousov et al., 2002).

More than one-third of the global population is infected with MTB. However, only $10 \%$ develop the clinical disease. Many factors contribute to the immune response against tuberculosis. The solute carrier family 11 member 1 gene (SLC11A1, formerly

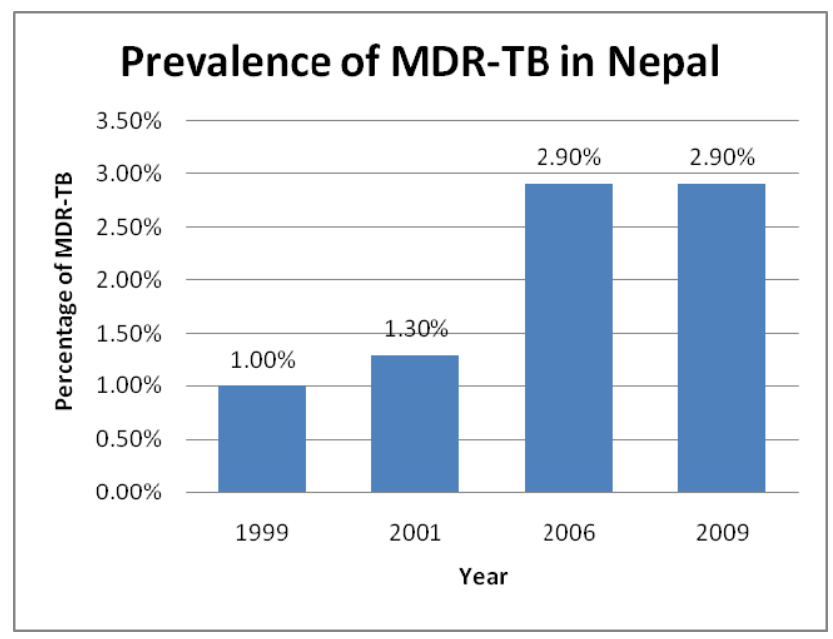

known as NRAMP1: natural resistance associated macrophage protein 1 ) is one of the candidate genes for susceptibility to human tuberculosis (Takahashi et al., 2008). The gene is located on human chromosome 2q35 and has 15 exons spanning about $14 \mathrm{~kb}$ (Marquet et al., 2000). The gene encodes a transmembrane protein expressed exclusively in macrophages/ monocytes and polymorphonuclear leukocytes. The protein acts as a transporter for divalent cations $\mathrm{Fe}^{2+}$, $\mathrm{Zn}^{2+}$ and $\mathrm{Mn}^{2+}$ and has pleiotropic effects on macrophage activation (Goswami et al., 2001). Studies have demonstrated an association between three different polymorphisms (INT4, D543N and 3'UTR) in SLC11A1 and pulmonary TB (Taype et al., 2006).

In the present study, Ser315Thr KatG mutation in the MDR-TB culture samples and G/C polymorphisms in INT4 region of SLC11A1 of TB patients were studied using Polymerase Chain Reaction (PCR) - Restriction Fragment Length Polymorphism (RFLP) technique.

\section{Materials and Methods}

Study samples. 24 MTB Culture (all AFB stain positive) samples were obtained from GENTUP, Kathmandu. The cultured samples comprised of both pulmonary and extra-pulmonary origin. Drug Susceptibility Testing was also carried out in GENTUP and all of the 24 samples were graded as MDR-TB. 24 whole blood samples of MDR-TB patients were also obtained for SLC11A1 analysis. The samples were collected from the Central Development Region of Nepal. However, we were unable to obtain the clinical history of the test subjects. Further molecular analysis was carried out in a BSL-III laboratory at Genetics Nepal Pvt. Ltd., Lalitpur, Nepal.

Genomic DNA isolation of $M$. tuberculosis. DNA isolation from cultured samples was done using SORPO clean $^{T M}$ Genomic DNA extraction kit. A loop full of bacterial colonies from the culture samples were suspended in $200 \mu \mathrm{l}$ of sterile water. A spin column extraction was carried out as prescribed by the manufacturer.

Human genomic DNA isolation. The whole-blood samples from human test subjects were collected in EDTA coated vial and immediately centrifuged at $5000 \mathrm{rpm} / 5 \mathrm{~min}$. Plasma was separated and $200 \mu \mathrm{l}$ of

Figure 1: Prevalence of MDR-TB in Nepal.

(Source: NTC, 2009) 
whole-blood was taken as sample for further processing. SORPO clean ${ }^{\mathrm{TM}}$ Genomic DNA extraction kit was used for genomic DNA isolation. All the other steps were same as described above.

Genomic DNA visualization: The extracted DNA was visualized in a $0.8 \%$ agarose (Amresco ${ }^{\circ}$ ) gel.

PCR-RFLP analysis: Amplification of the $200 \mathrm{bp}$ fragment with KatG codon 315 (the fragment in KatG from nucleotide positions 904 to 1103; http:// genolist.pasteur.fr/TubercuList) was performed in TPersonal Thermocycler (Biometra) with primers katG1F and katG4RB (Mokrousov et al., 2002) (Table 1) in $25 \mu \mathrm{l}$ of a PCR mixture $(0.4 \mu \mathrm{M}$ of each primers, $2.5 \mathrm{mM}$ of dNTP mix, $1 \mathrm{U}$ of recombinant Taq DNA polymerase (Fermentas ${ }^{\circ}$ ) and $2.5 \mathrm{mM}$ of $\mathrm{MgCl}_{2}$ ) under the following conditions: initial denaturation at $94^{\circ} \mathrm{C}$ for $5 \mathrm{~min}$; 30 cycles of $94^{\circ} \mathrm{C}$ for $1 \mathrm{~min}, 56^{\circ} \mathrm{C}$ for $45 \mathrm{sec}$ and $72{ }^{\circ} \mathrm{C}$ for $45 \mathrm{sec}$; and a final elongation at $72^{\circ} \mathrm{C}$ for 5 min. The amplified fragment was assessed by electrophoresis in a $2 \%$ agarose gel and cleaved with restriction enzyme Mspl (Hpall) (Fermentas') as per the instructions of the manufacturer. The restriction fragments obtained were electrophoresed in a $2 \%$ agarose gel and were visualized under ultra-violet (UV) light on a transilluminator (Biometra ). M. tuberculosis H37Rv was taken as the reference strain for this study.

PCR-RFLP assay was designed to detect the KatG codon mutation $\mathrm{AGC}(\mathrm{Ser})$ à $\mathrm{ACC}(\mathrm{Thr})$, which leads to the INH resistant phenotype. This mutation creates an additional Mspl site (CCGG) and thus can be detected by use of this restriction endonuclease. As a result, the longest fragment size in the wild type KatG product would be $153 \mathrm{bp}$ and in Ser315Thr KatG mutant the longest fragment would be 132 bp which could be easily resolved in a $2 \%$ agarose gel while the shorter bands (21 bp - 8 bp) cannot be resolved in the gel (Figure 2).

Similarly, 514 bp of INT4 region of SLC11A1 gene was amplified using primers INT4F and INT4R (Taype et al., 2006) (Table 1). A $25 \mu \mathrm{l}$ of a PCR mixture $(0.4 \mu \mathrm{M}$ of each primers, $2.5 \mathrm{mM}$ of dNTP mix, $1 U$ of recombinant Taq DNA polymerase and $2.5 \mathrm{mM}$ of $\mathrm{MgCl}_{2}$ ) was prepared and the reaction was carried out under the following condition: initial denaturation at $95^{\circ} \mathrm{C}$ for 5 min; 30 cycles of $94^{\circ} \mathrm{C}$ for $1 \mathrm{~min}, 61^{\circ} \mathrm{C}$ for $1 \mathrm{~min}$ and $72^{\circ} \mathrm{C}$ for $1 \mathrm{~min}$; and a final elongation at $72^{\circ} \mathrm{C}$ for $4 \mathrm{~min}$. The amplified fragment was assessed by electrophoresis in a $2 \%$ agarose gel. To analyze the G/C polymorphisms in INT4, the amplified products were cleaved with restriction enzyme Apal (Fermentas ${ }^{\circledR}$ ) as per the instructions of the manufacturer. The restriction fragments obtained were electrophoresed in a $2 \%$ agarose gel and were visualized under UV light on a transilluminator.

\section{Results:}

Genomic DNA visualization: All the extracted DNA samples displayed a positive band when they were electrophoresed in $0.8 \%$ agarose gel. (Figure 3 and 4)

PCR-RFLP analysis: All the 24 MTB DNA samples were observed to have a positive amplification for KatG gene fragment. An amplicon of 200 bp size were observed in a $2 \%$ agarose gel (Figure 5). In the electrophoresis of the KatG amplified product digested with Mspl, 4 (samples 015, 016, 020 and 024) out of 24 samples were obtained at $132 \mathrm{bp}$ region indicating the occurrence of Ser315Thr mutation whereas rest of the 20 samples were obtained at 153 bp region indication no Ser315Thr mutation (Figure 6). Gel picture of samples 015 and 016 are not shown.

All the 24 human DNA samples from whole blood had a positive amplification at $514 \mathrm{bp}$ region for INT4 (Figure 7). When these amplicons were subjected to Apal digestion, all of the 24 samples were observed at 514 bp region indicating no $\mathrm{G} / \mathrm{C}$ polymorphisms in INT4 region of SLC11A1 (Figure 8).

\section{Discussion}

South Asia holds around $40 \%$ of the global TB burden and Nepal has no different scenario. The Millennium Development Goal (MDG) aims to eliminate TB as a public health problem (1 case per million population) by 2050 . Nepal has made satisfactory progress towards MDG. However, the challenges to address the growing burden of TB and MDR-TB population are yet far away. Nepal still lacks the health care facilities and access to modern diagnostic technologies is very poor in the area (Basnet et al., 2009). Although Directly Observed Treatment, Short-course (DOTS) strategy has significantly contributed towards the treatment of TB, a lack of rapid and sensitive rapid and sensitive methods of detection is a major hindrance to the ongoing battle against the disease.

AFB microscopy is the primary screening tool for TB and culture of mycobacteria is still regarded as the "gold standard" in TB diagnosis. But these days new 
Table 1. Primer sequence for KatG and INT4

\begin{tabular}{|c|c|c|}
\hline Target Gene Region & Primer & \multicolumn{1}{c|}{ Sequence } \\
\hline \multirow{2}{*}{ KatG } & katG1F & 5'-AGCTCGTATGGCACCGGAAC-3' \\
\cline { 2 - 3 } & katG4RB & 5'-AACGGGTCCGGGATGGTG-3' \\
\hline \multirow{2}{*}{ INT4 } & INT4F & 5'-GTCTGCCATCTCTACTACCCTAAGGTG-3' \\
\cline { 2 - 3 } & INT4R & 5'-CATGTCCCTCTAGGTATGTGCTATCAG-3' \\
\hline
\end{tabular}

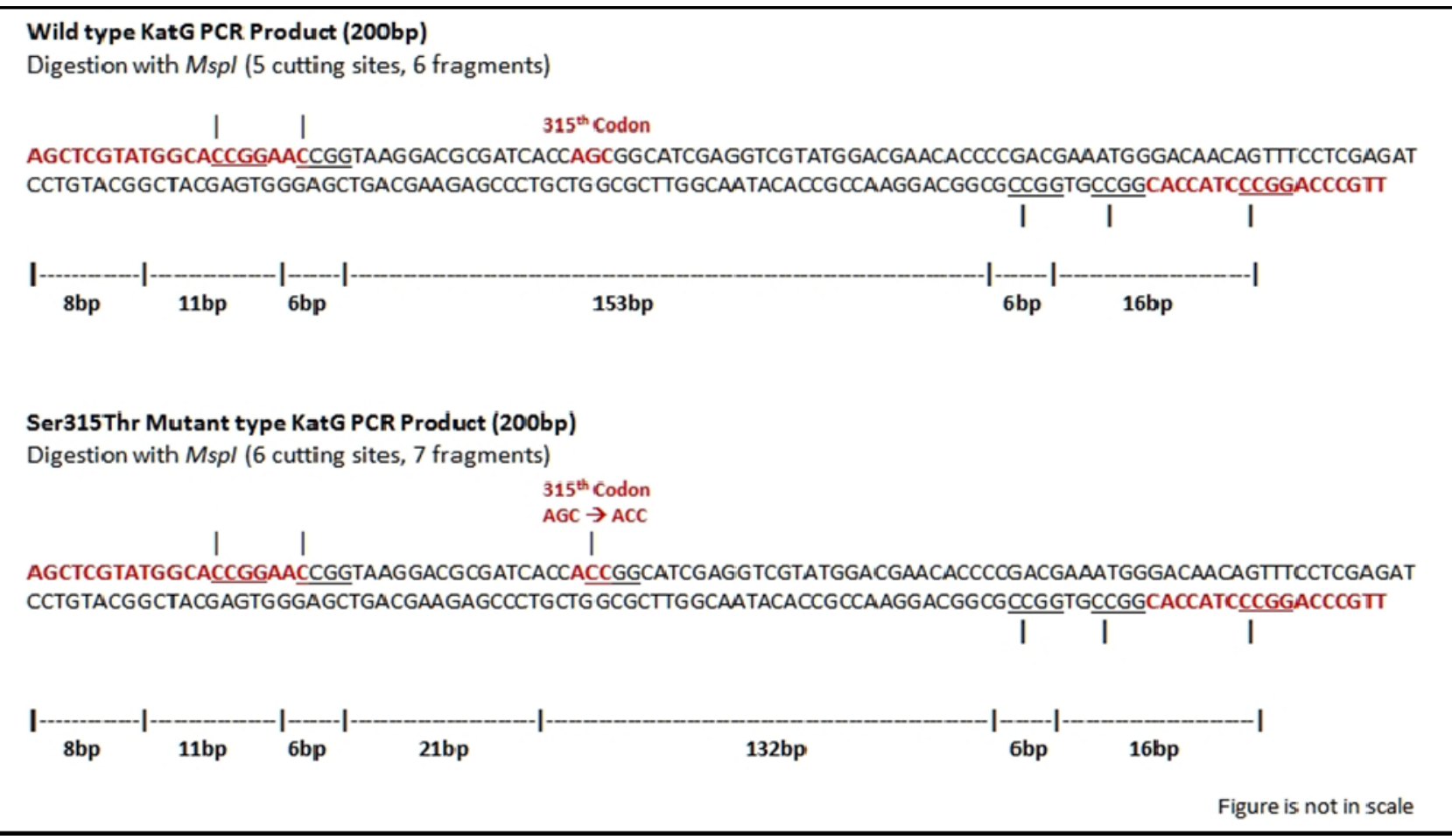

Figure 2. Schematic illustration of the KatG 200-bp fragment amplified with primers katG1F and katG4RB. The vertical line represents the Mspl restriction site (CCGG). In the wild-type KatG PCR product there is no Mspl restriction site at $315^{\text {th }}$ Codon (AGC) and the longest fragment is of $153 \mathrm{bp}$. But in the Mutant KatG PCR product there is an addition of $\mathrm{Msp} /$ restriction site at $315^{\text {th }}$ codon (ACC) and it gives $132 \mathrm{bp}$ band as the longest fragment.

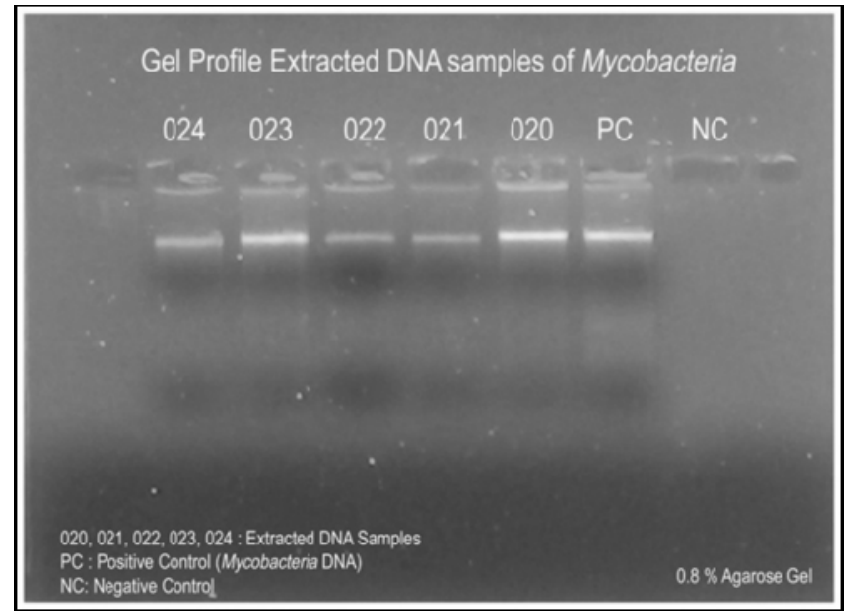

Figure 3. Visualization of the extracted MTB DNA from cultured sample in a $0.8 \%$ agarose gel. 020-024 are the DNA samples, PC is the Positive Control and NC is the Negative Control. The bands are very close to the loading well indicating the larger fragment of genomic DNA.

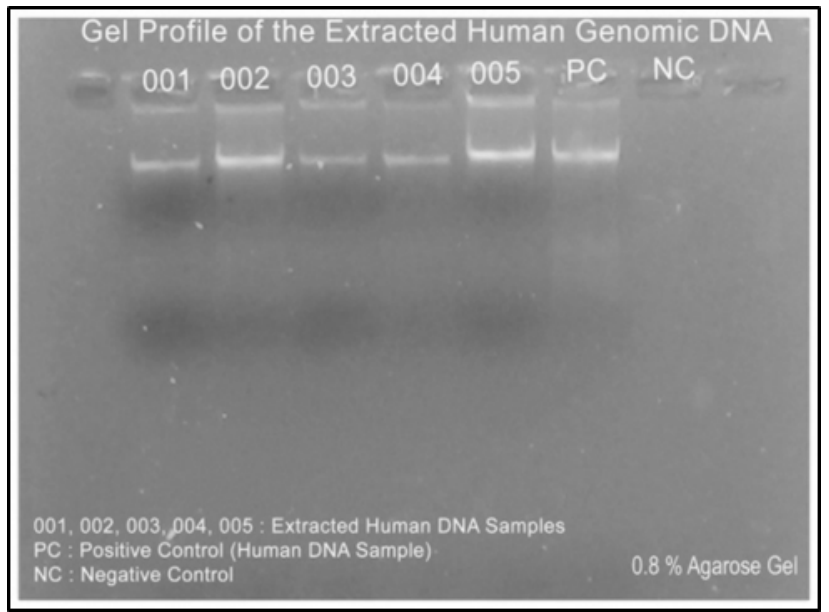

Figure 4. Visualization of the extracted DNA sample from Human whole blood in a 0.8\% agarose gel. 001-005 are the DNA samples, PC is the Positive Control and NC is the Negative Control. The bands are very close to the loading well indicating the larger fragment of genomic DNA. 
molecular diagnostic tools are promoted globally mostly in the detection of MTB, drug monitoring and in MDR-TB diagnosis (Pai et al., 2006). This is due to many advantages of molecular genomic tools over conventional diagnostic methods that lack the speed,

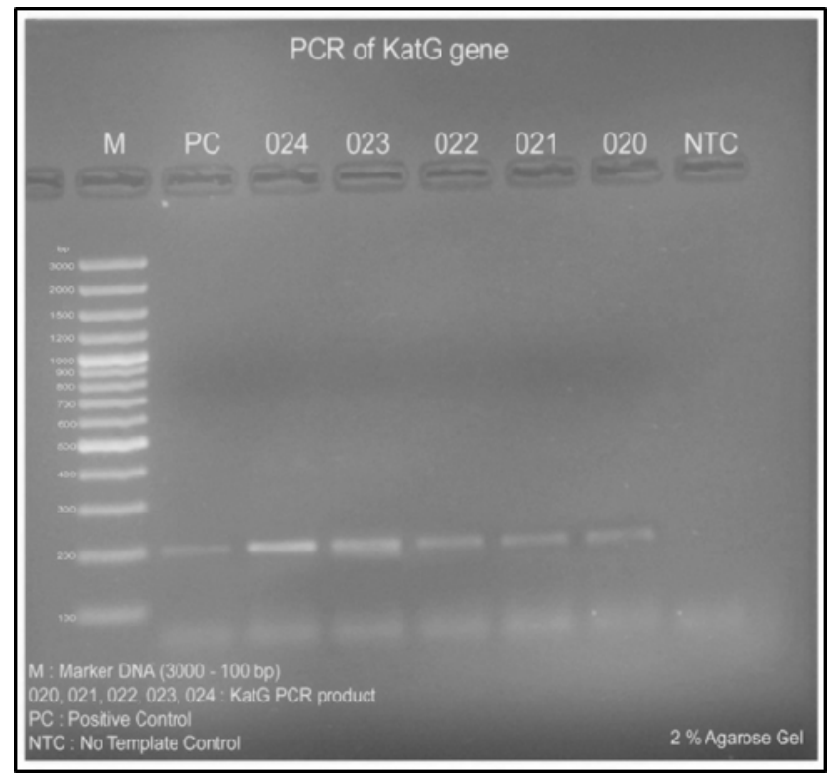

Figure 5. PCR product of KatG gene fragment visualized in a $2 \%$ agarose gel. $020-024$ are the MTB samples, PC is the Positive Control and NTC is the No Template Control. All the samples have positive band amplification at $200 \mathrm{bp}$ region.

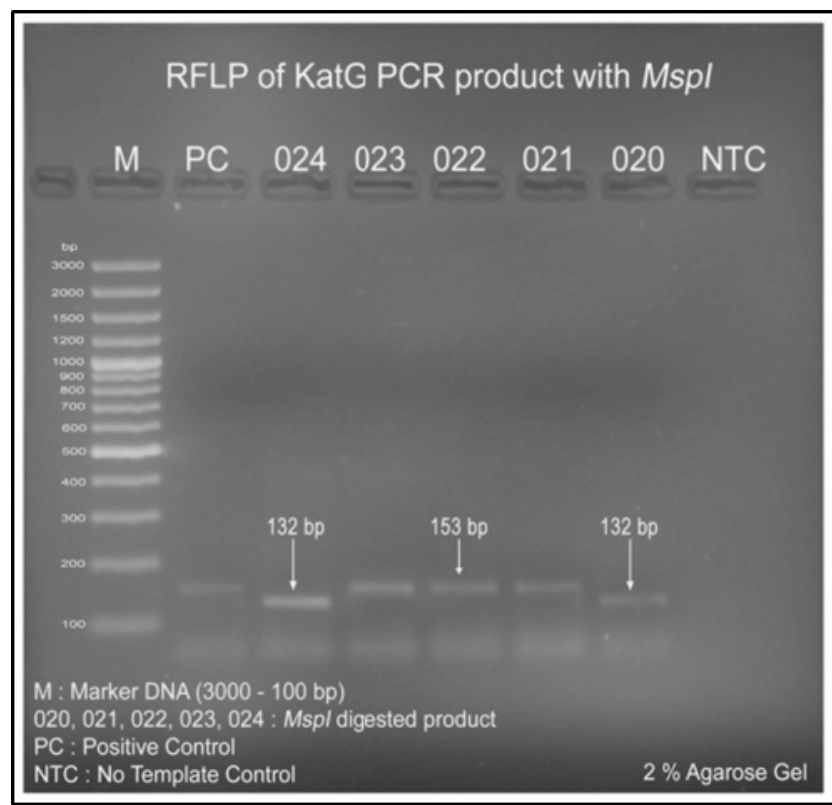

Figure 6.Mspl digested product of KatG gene fragment visualized in a $2 \%$ agarose gel. $020-024$ are the MTB samples, PC is the Positive Control and NTC is the No Template Control. Samples 021, 022, and 023 has a band size of $153 \mathrm{bp}$ indicating no mutation at $315^{\text {th }}$ codon position where as sample 020 and 024 has a band sized 132 bp indicating SeràThr mutation at $315^{\text {th }}$ codon position of KatG gene. sensitivity and specificity.

The present study looks at the resistance in the KatG Ser315Thr towards a popular anti-TB drug isoniazid. This is just one among many possible mutations in KatG accounting for INH resistance. 4 (16.67\%) samples

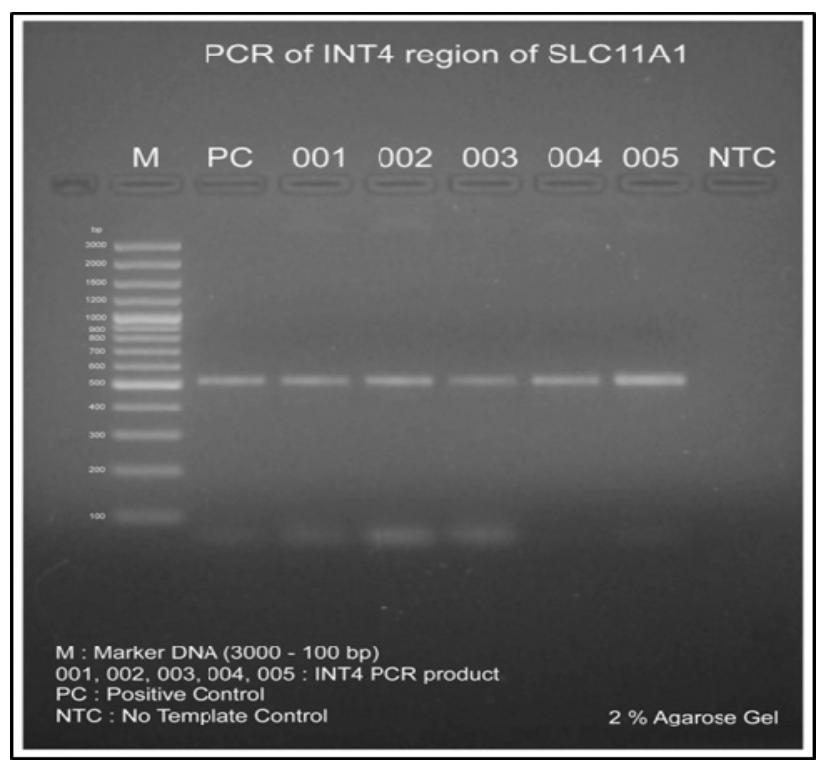

Figure 7. PCR product of INT4 gene fragment visualized in a 2\% agarose gel. 001-005 are the human DNA samples, PC is the Positive Control and NTC is the No Template Control. All the samples has positive band amplification at $514 \mathrm{bp}$ region

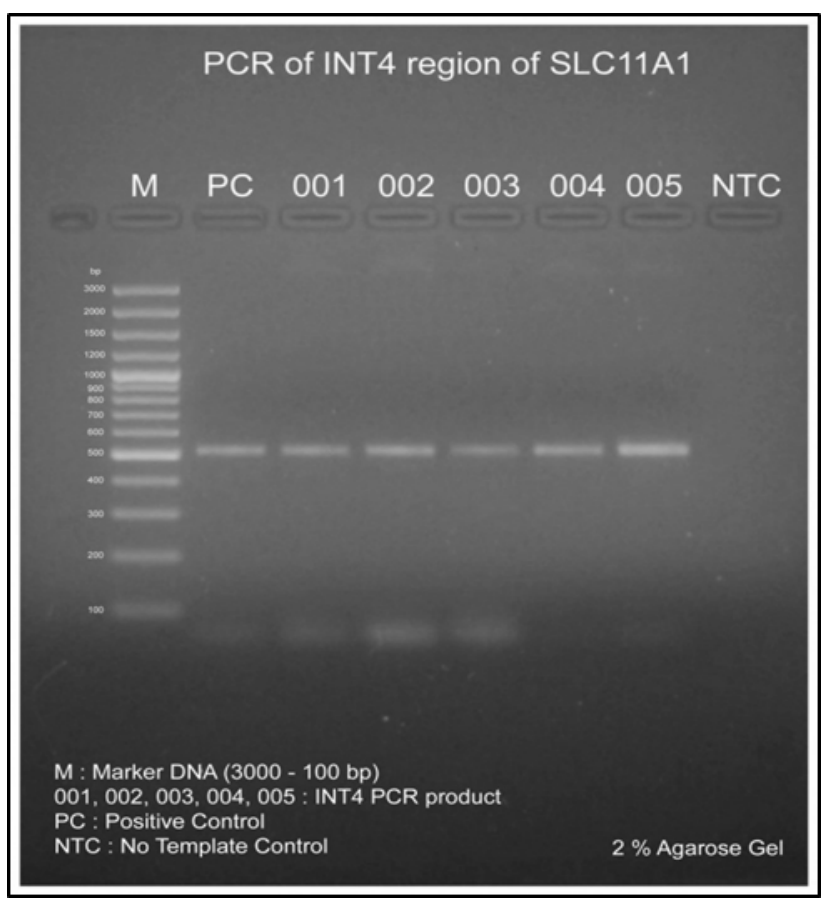

Figure 8. Apal digested product of INT4 gene fragment visualized in a 2\% agarose gel. 001-002 are the Human DNA samples, PC is the Positive Control and NTC is the No Template Control. All the samples were observed at 514 bp region indicating no $\mathrm{G} / \mathrm{C}$ polymorphisms in INT4 region of SLC11A1 gene 
Table 2. Relationship between AFB Stain, MTB Culture and PCR-RFLP Results

\begin{tabular}{|c|c|c|c|c|c|c|} 
Sample ID & AFB Stain & MTB Culture & MDR-TB & $\begin{array}{c}\text { KatG PCR ampli- } \\
\text { con size (bp) }\end{array}$ & $\begin{array}{c}\text { Mspl digested } \\
\text { product size } \\
\text { (bp) }\end{array}$ & $\begin{array}{c}\text { Ser315Thr KatG } \\
\text { mutation }\end{array}$ \\
\hline MTB-001 & POSITIVE & POSITIVE & POSITIVE & 200 & 153 & NEGATIVE \\
\hline MTB-002 & POSITIVE & POSITIVE & POSITIVE & 200 & 153 & NEGATIVE \\
\hline MTB-003 & POSITIVE & POSITIVE & POSITIVE & 200 & 153 & NEGATIVE \\
\hline MTB-004 & POSITIVE & POSITIVE & POSITIVE & 200 & 153 & NEGATIVE \\
\hline MTB-005 & POSITIVE & POSITIVE & POSITIVE & 200 & 153 & NEGATIVE \\
\hline MTB-006 & POSITIVE & POSITIVE & POSITIVE & 200 & 153 & NEGATIVE \\
\hline MTB-007 & POSITIVE & POSITIVE & POSITIVE & 200 & 153 & NEGATIVE \\
\hline MTB-008 & POSITIVE & POSITIVE & POSITIVE & 200 & 153 & NEGATIVE \\
\hline MTB-009 & POSITIVE & POSITIVE & POSITIVE & 200 & 153 & NEGATIVE \\
\hline MTB-010 & POSITIVE & POSITIVE & POSITIVE & 200 & 153 & NEGATIVE \\
\hline MTB-011 & POSITIVE & POSITIVE & POSITIVE & 200 & 153 & NEGATIVE \\
\hline MTB-012 & POSITIVE & POSITIVE & POSITIVE & 200 & 153 & NEGATIVE \\
\hline MTB-013 & POSITIVE & POSITIVE & POSITIVE & 200 & 153 & NEGATIVE \\
\hline MTB-014 & POSITIVE & POSITIVE & POSITIVE & 200 & 153 & NEGATIVE \\
\hline MTB-015 & POSITIVE & POSITIVE & POSITIVE & 200 & 132 & POSITIVE \\
\hline MTB-016 & POSITIVE & POSITIVE & POSITIVE & 200 & 132 & POSITIVE \\
\hline MTB-017 & POSITIVE & POSITIVE & POSITIVE & 200 & 153 & NEGATIVE \\
\hline MTB-018 & POSITIVE & POSITIVE & POSITIVE & 200 & 153 & NEGATIVE \\
\hline MTB-019 & POSITIVE & POSITIVE & POSITIVE & 200 & 153 & NEGATIVE \\
\hline MTB-020 & POSITIVE & POSITIVE & POSITIVE & 200 & 132 & POSITIVE \\
\hline MTB-021 & POSITIVE & POSITIVE & POSITIVE & 200 & 153 & NEGATIVE \\
\hline MTB-022 & POSITIVE & POSITIVE & POSITIVE & 200 & 153 & NEGATIVE \\
\hline MTB-023 & POSITIVE & POSITIVE & POSITIVE & 200 & 153 & NEGATIVE \\
\hline MTB-024 & POSITIVE & POSITIVE & POSITIVE & 200 & 132 & POSITIVE \\
\hline & & & & & \\
\hline
\end{tabular}

out of 24 MTB culture samples demonstrated Ser315Thr KatG mutation (i.e. these samples were INH resistant). It indicates that there could possibly be significantly high anti-TB drug resistant population if screened in a larger population. One of the drawbacks of this study is that other mutation in various genes (InhA, OxyR, AhpC) that contributes to the INH resistance were not studied. Studies have reported that even if there is Ser315Ther KatG mutation, it does not necessarily account to INH resistance and have an overall high level of catalase activity (Guo et al., 2006). Both the catalase activity and drug sensitivity information could not be obtained.

The association between SLC11A1 polymorphisms and susceptibility to tuberculosis has been described in many studies, which showed positive association in some, while no association in others (Takahashi et al., 2008). A study showed that NRAMP1 polymorphisms may be associated with progression to severe forms of pulmonary tuberculosis rather than with susceptibility to M. tuberculosis infection (Zhang et al., 2005). All the INT4 amplicons when subjected to Apal digestion, bands of $514 \mathrm{bp}$ were observed. If the INT4 region had $\mathrm{G} / \mathrm{C}$ polymorphisms then restriction site(s) would have been additionally created and the RFLP bands of $<500$ bp size would have been observed. This indicates that no $\mathrm{G} / \mathrm{C}$ polymorphism was present in the amplified

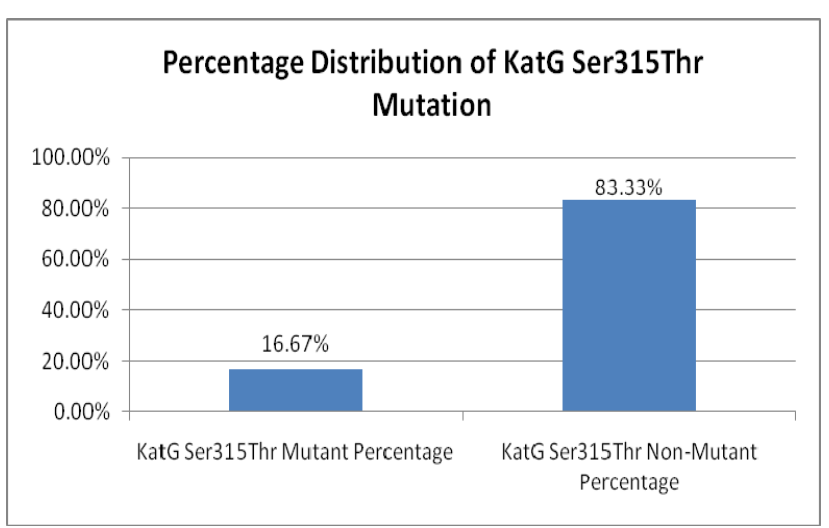

Figure 9. Percentage Distribution of KatG Ser315Thr Mutation 
Table 3. Relationship MDR-TB and G/C polymorphism in INT4 region of SLC11A1

\begin{tabular}{|c|c|c|c|c|}
\hline SamplelD & MDR-TB & $\begin{array}{l}\text { INT4 PCR amplicon size } \\
\text { (bp) }\end{array}$ & $\begin{array}{l}\text { Apal digested product of } \\
\text { INT4 (bp) }\end{array}$ & G/C Polymorphism in INT4 \\
\hline SLC-001 & POSITIVE & 514 & 514 & NEGATIVE \\
\hline SLC-002 & POSITIVE & 514 & 514 & NEGATIVE \\
\hline SLC-003 & POSITIVE & 514 & 514 & NEGATIVE \\
\hline SLC-004 & POSITIVE & 514 & 514 & NEGATIVE \\
\hline SLC-005 & POSITIVE & 514 & 514 & NEGATIVE \\
\hline SLC-006 & POSITIVE & 514 & 514 & NEGATIVE \\
\hline SLC-007 & POSITIVE & 514 & 514 & NEGATIVE \\
\hline SLC-008 & POSITIVE & 514 & 514 & NEGATIVE \\
\hline SLC-009 & POSITIVE & 514 & 514 & NEGATIVE \\
\hline SLC-010 & POSITIVE & 514 & 514 & NEGATIVE \\
\hline SLC-011 & POSITIVE & 514 & 514 & NEGATIVE \\
\hline SLC-012 & POSITIVE & 514 & 514 & NEGATIVE \\
\hline SLC-013 & POSITIVE & 514 & 514 & NEGATIVE \\
\hline SLC-014 & POSITIVE & 514 & 514 & NEGATIVE \\
\hline SLC-015 & POSITIVE & 514 & 514 & NEGATIVE \\
\hline SLC-016 & POSITIVE & 514 & 514 & NEGATIVE \\
\hline SLC-017 & POSITIVE & 514 & 514 & NEGATIVE \\
\hline SLC-018 & POSITIVE & 514 & 514 & NEGATIVE \\
\hline SLC-019 & POSITIVE & 514 & 514 & NEGATIVE \\
\hline SLC-020 & POSITIVE & 514 & 514 & NEGATIVE \\
\hline SLC-021 & POSITIVE & 514 & 514 & NEGATIVE \\
\hline SLC-022 & POSITIVE & 514 & 514 & NEGATIVE \\
\hline SLC-023 & POSITIVE & 514 & 514 & NEGATIVE \\
\hline SLC-024 & POSITIVE & 514 & 514 & NEGATIVE \\
\hline
\end{tabular}

region of INT4. The present study shows no significant association between G/C polymorphism INT4 region of SLC11A1 with TB. With the limited number of samples and failure to study D543N and 3'UTR region, the role of SLC11A1 in susceptibility towards TB cannot overruled. As WHO claims one-third of the world's population to be infected with latent form of $T B$, SLC11A1 polymorphisms can be accredited to be a helping factor for TB susceptibility or progression.

This study has considered $M$. tuberculosis H37Rv as a reference strain but other clinical strain could also have been prevalent. This fact remained as a challenge

\section{Reference}

World Health Organization. Global Tuberculosis Control. A short update to the 2009 report. 2009

World Health Organization. Multidrug and extensively drug-resistant TB (M/XDR-TB) 2010 Global Report on Surveillance and Response. 2010 to our study as no base-line study on MTB strain genotyping has been conducted for Nepalese MTB isolates till date.

\section{Conclusion}

The findings in this study suggests that still more people could be properly diagnosed for the actual drug resistance mutations utilizing molecular genomic diagnostic tools. Further study with a greater number of MDR-TB patients is needed to get the actual scenario of TB population of Nepal.

National Tuberculosis Center. National Tuberculosis Control Programme Nepal - Annual Report FY 2065/66 (2008/2009). 2009

Musser JM. Antimicrobial agent resistance in mycobacteria: molecular genetic insights. Clin Microbiol Rev. 1995 Oct;8(4):496-514. 
Rattan A, Kalia A, Ahmad N. Multidrug-resistant Mycobacterium tuberculosis: molecular perspectives. Emerg Infect Dis. 1998 Apr-Jun;4 (2):195-209.

Mokrousov I, Narvskaya O, Otten T, Limeschenko E, Steklova L, Vyshnevskiy B. High prevalence of KatG Ser315Thr substitution among isoniazid-resistant Mycobacterium tuberculosis clinical isolates from northwestern Russia, 1996 to 2001. Antimicrob Agents Chemother. 2002 May;46(5):1417-24.

Takahashi K, Hasegawa Y, Abe T, Yamamoto T, Nakashima K, Imaizumi K, Shimokata K. SLC11A1 (formerly NRAMP1) polymorphisms associated with multidrug-resistant tuberculosis. Tuberculosis (Edinb). 2008 Jan;88(1):52-7.

Marquet S, Lepage P, Hudson TJ, Musser JM, Schurr E. Complete nucleotide sequence and genomic structure of the human NRAMP1 gene region on chromosome region 2q35. Mamm Genome 2000, 11:755-762.

Goswami T, Bhattacharjee A, Babal P, Searle S, Moore E, Li M, Blackwell JM. Natural-resistanceassociated macrophage protein 1 is an $\mathrm{H}+$ /bivalent cation antiporter. Biochem J 2001; 354: 511-519.

Taype CA, Castro JC, Accinelli RA, Herrera-Velit P, Shaw MA, Espinoza JR. Association between SLC11A1 polymorphisms and susceptibility to different clinical forms of tuberculosis in the Peruvian population. Infect Genet Evol. 2006 Sep;6(5):361-7.

Pai M, Kalantri S, Dheda K. New tools and emerging technologies for the diagnosis of tuberculosis: part II. Active tuberculosis and drug resistance. Expert Rev Mol Diagn. 2006 May;6(3):423-32.

Basnet R, Hinderaker SG, Enarson D, Malla P, Mørkve O. Delay in the diagnosis of tuberculosis in Nepal. BMC Public Health. 2009 Jul 14;9:236.

Guo H, Seet Q, Denkin S, Parsons L, Zhang Y. Molecular characterization of isoniazid-resistant clinical isolates of Mycobacterium tuberculosis from the USA. J Med Microbiol. 2006 Nov;55(Pt 11):1527-31.

Zhang W, Shao L, Weng X, Hu Z, Jin A, Chen S, Pang M, Chen ZW. Variants of the natural resistanceassociated macrophage protein 1 gene (NRAMP1) are associated with severe forms of pulmonary tuberculosis. Clin Infect Dis. 2005 May 1;40(9):12326. Epub 2005 Mar 23. 